\title{
Somatization, obsessive-compulsive symptoms, and job satisfaction of the prison medical workers in Jiangxi, China
}

This article was published in the following Dove Press journal:

Psychology Research and Behavior Management

\author{
Xiaojun Liu',2 \\ Dongdong Jiang' \\ Baojing $\mathrm{Li}^{\prime}$ \\ Yuanan $\mathrm{Lu}^{2,3}$ \\ Zongfu Mao',2
}

'Department of Social Medicine and Health Management, School of Health Sciences, Wuhan University, Wuhan 43007I, China; ${ }^{2}$ Global Health Institute, Wuhan University, Wuhan 43007I, China; ${ }^{3}$ Department of Public Health, University of Hawaii at Mānoa, Honolulu, HI, USA
Correspondence: Zongfu Mao Global Health Institute, Wuhan University, II5\# Donghu Road, Wuhan 43007I, China

Tel +8618089562702

Fax +8618089565818

Email zfmao@whu.edu.cn
Purpose: This study evaluated the current situation and possible influencing factors associated with prison medical workers' (PMWs') somatization, obsessive-compulsive symptoms, and their job satisfaction.

Participants and methods: The Chinese version of Symptom Checklist-90-R (SCL-90-R) was used to assess PMWs' mental health conditions. Logistic regression analysis was used to identify the main factors associated with PMWs' somatization, obsessive-compulsive symptoms, and their job satisfaction. The correlations between PMWs' somatization, obsessive-compulsive symptoms, and job satisfaction were examined.

Results: The positive detection rates of somatization and obsessive-compulsive symptoms among the PMWs were $22.73 \%$ and $47.27 \%$, respectively. Age, educational level, and length of working in prison were factors related to the PMWs' mental health. Half of the PMWs were not satisfied with their current job, particularly the females and young workers with a shorter period of service. PMWs' somatization is strongly positively correlated with obsessive-compulsive symptoms, while job satisfaction is negatively correlated with having somatization symptoms and obsessive-compulsive disorders.

Conclusion: PMWs with lower educational level, elderly workers, and new employees have higher risk and more serious somatization and obsessive-compulsive symptoms. The female and young PMWs with a short service time were particularly not satisfied with their job. Findings from this study indicated that it is important and necessary to improve PMWs' job satisfaction in order to reduce their somatization symptoms and obsessive-compulsive disorders.

Keywords: prison medical workers, somatization, obsessive-compulsive symptoms, job satisfaction

\section{Introduction}

Somatization and obsessive-compulsive symptoms are important components of mental health. Somatization is the tendency for individuals to experience and express physical discomfort or symptoms under psychological stress, which cannot be diagnosed through disease. The main symptoms of somatization are lumbar pain, muscular pain, and weakness. ${ }^{1,2}$ The symptoms of obsessive-compulsive disorder are characterized by coexistence of the conscious self-coercion and conscious self-opposing. Once the sense of imperfection, insecurity, and uncertainty are prominent, people may easily show obsessive-compulsive symptoms. . $^{3,4}$

Previous related studies have investigated the psychological health for different populations. The main target subjects in China include students, patients with different diseases, soldiers, the elderly, and the general population. ${ }^{5-10}$ Prison medical 
workers (PMWs) in China hold multiple professional jobs as both the prison police force and the health care provider and psychological counselor, and thus they may play different roles at the same time. PMWs work in the prison where the prisoners are forcibly confined. Prison is relatively isolated and normally surrounded by fencing, high walls, earthworks, or other barriers to prevent escape. Because of the special working environment and the nature of the working condition, this special kind of police group in China, the PMWs, need to assist the prison police officers in carrying out the prison management when they are providing medical services or psychological counseling for the prisoners. In addition, PMWs are sometimes faced with the potential harms or threats, especially when they are dealing with prison break, suicide, fights, and other complications caused by the prisoners. Given these uncertainties, PMWs are often overloaded, stressed, and deal with high pressure due to security uncertainty, which may cause many adverse health effects, such as lack of work enthusiasm, low job satisfaction with strong job burnout, and even mental health disorders like somatization, obsessive-compulsive symptoms, interpersonal sensitivity, phobic anxiety, etc.

However, these important issues have not been studied seriously in China, and there is no related study that addresses this topic. Therefore, we performed this research with special emphasis on the PMWs' somatization, obsessive-compulsive symptoms, and their job satisfaction. In this paper, we particularly selected the PMWs in Jiangxi province of China as our study subjects and employed the Chinese version of Symptom Checklist-90-R (SCL-90-R) to assess the diagnoses of PMWs' somatization, obsessive-compulsive disorder, and their job satisfaction. This paper represents the first study in China that addresses the current status of the PMWs' somatization, obsessive-compulsive disorder, and their job satisfaction and the associated possible influencing factors. Moreover, we also examined the correlations between somatization, obsessivecompulsive symptoms, and job satisfaction in the PMWs.

\section{Participants and methods}

\section{Participants}

There are about 500 PMWs officially hired by the government in Jiangxi. In order to ensure the representativeness of the sample, we distributed 350 questionnaires to affiliated hospitals or medical centers of the prison system, which accounts for $70 \%$ of the total number of employees. A total of 330 valid questionnaires were collected and used for data analysis, which accounts for $66 \%$ of the total number of employees.

\section{Study protocol and procedure}

Prior to conducting this cross-sectional survey study, we obtained permissions and assistance from the local authorities and partner institutions, including the School of Public Health of Nanchang University and Provincial Prison Central Hospital of Jiangxi. We distributed our survey papers to our targeted individuals, and the potential participants were asked to answer the questionnaires independently and anonymously. The finished questionnaires were checked to ensure the effectiveness of the questionnaires, and the incomplete or doubtful questionnaires were not used.

\section{Survey tools}

The questionnaire employed for this survey study consisted of the following 3 parts:

1. Sociodemographic characteristics, including the participants' gender (male/female), marital status, age, educational level, and duration of their work history in prisons.

2. The Chinese version of the SCL-90-R. ${ }^{11,12}$ The good internal consistency and reliability of Chinese version SCL-90-R have been confirmed, ${ }^{13-16}$ and it is widely used in China to evaluate a broad range of psychological problems and symptoms of psychopathology. In the current study, the Cronbach's $\alpha$ coefficient was 0.92 . The scale consists of 9 dimensions with 90 questions including ones on somatization, obsessive-compulsive symptoms, interpersonal sensitivity, depression, anxiety, hostility, phobic anxiety, paranoid ideation, and psychoticism. A 5-point Likert scale was used to record each questions. Scores for individual dimensions that are $>2$ points should be considered positive and need further professional diagnosis.

3. The job satisfaction was measured with 1 single question as "How satisfied are you with your current job." This question had 7 classified ordinal variables, namely, strongly dissatisfied $=1$, dissatisfied $=2$, somewhat dissatisfied $=3$, neither satisfied nor dissatisfied $=4$, somewhat satisfied $=5$, satisfied $=6$, and strongly satisfied $=7$.

For the purposes of this paper, we only selected 2 dimensions of the Chinese version SCL-90-R - somatization and obsessive-compulsive symptoms.

\section{Quality control}

We asked our targeted individuals to answer the questionnaires anonymously, with no mention of personal details, and to fill out the survey questions independently based on their inner true feelings. Prior to the implementation of the 
survey, both our own research members and the coadjutants from local authorities and partner institutions were trained to use the unified guidance language. During the implementation of the survey, we also made a very clear explanation of the purpose and significance of this study to potential participants every time, and answered the questions raised by participants. The finished questionnaires were checked by our own research members to ensure the effectiveness of the questionnaires. We also rejected these questionnaires that were poorly completed, such as those having the same/ exact answers to all the questions, or those having many questions ( $>5 \%)$ with no answer. Lastly, we used EpiData 3.1 (The EpiData Association, Odense, Denmark) to set up the database, and double entry and logical verification of the questionnaires were done to ensure the accuracy of the data.

\section{Statistical analysis}

Statistical Package for the Social Sciences (SPSS) version 20.0 for Windows (IBM Corporation, Armonk, NY, USA) was employed to run all statistical analysis work. A $p$-value $<0.05$ was considered as statistical significant.

Data analysis was performed in 4 steps: First, both categorical variables and metric variables were summarized via initial descriptive analysis. Frequencies with proportions and mean values with SDs were presented (Table 1). Then, PMWs' somatization, obsessive-compulsive symptoms, job satisfaction, and their potential factors were assigned (Table 2). Next, both univariate and multivariate analysis were performed by using binary logistic regression analyses to identify the main factors that affect the PMWs' somatization, obsessive-compulsive symptoms, and their job

Table I Descriptions of the variables $(n=330)$

\begin{tabular}{lll}
\hline Categorical variables & Frequency & Percentage (\%) \\
\hline Gender & & \\
$\quad$ Male & 153 & 46.36 \\
$\quad$ Female & 177 & 53.64 \\
Marital status & & \\
$\quad$ Married & 231 & 70.00 \\
$\quad$ Others & 99 & 30.00 \\
Education level & & \\
$\quad$ Bachelor's degree & 69 & 20.91 \\
$\quad \geq$ Bachelor's degree & 261 & 79.09 \\
Metric variables & Mean & SD \\
Age & 33.65 & 8.94 \\
Employment length & 12.37 & 8.42 \\
Somatization & 1.54 & 0.53 \\
Obsessive-compulsive symptoms & 2.04 & 0.69 \\
Job satisfaction & 3.49 & 1.65 \\
\hline
\end{tabular}

satisfaction. Both the crude odds ratio (COR) and adjusted odds ratio (AOR) value with a $95 \%$ CI were presented (Tables 3-5). Finally, Spearman correlation coefficients obtained from the Spearman's rank correlation analysis were used to describe the strength and direction of the relationship among somatization, obsessive-compulsive symptoms, and job satisfaction (Table 6).

\section{Ethical statement}

This study was conducted in accordance with the Declaration of Helsinki, and the study protocol was reviewed and approved by the institutional review board of School of Health Science, Wuhan University. The institutional review board of Provincial Prison Central Hospital of Jiangxi also reviewed and approved the study protocols. All participants reviewed and signed the consent form before they participated in the study.

\section{Results \\ Descriptions of variables}

The general characteristics of our subjects are shown in Table 1 ; a total of $153(46.36 \%)$ males were accounted for in a total sample size of 330. There were 99 (30.00\%) PMWs who were not married yet; only 69 (20.91\%) PMWs were educated to below the bachelor's degree level. The mean age of PMWs in Jiangxi was 33.65 years old, with a SD of 8.94. The PMWs' mean working history in the prison system was 12.37 years, with a SD of 8.42.

This survey revealed that PMWs received an average score of 1.54 points with a SD of 0.53 for somatization, and 2.04 points with a SD of 0.69 for obsessive-compulsive symptoms (ranging between 1 and 5 points). As for job satisfaction, the respondents' average score was 3.49 points with a SD of 1.65 (ranging between 1 and 7 points).

\section{Factors associated with PMWs' somatization}

According to the screening principle of the SCL-90-R, respondents' average score $>2$ points should be considered positive. Hence, the PMW's average scores were divided into 2 groups (negative and positive). PMWs' job satisfaction was deemed as unsatisfactory if the average score was between 1 and 3 and satisfactory if the average score was between 4 and 7. Using the detection rate of somatization, obsessivecompulsive symptoms, and job satisfaction as the dependent variables, the demographic characteristics were considered 
Table 2 Possible factors associated with PMWs' somatization, obsessive-compulsive symptoms, and job satisfaction and their assignment

\begin{tabular}{|c|c|c|}
\hline Variables & Assignment & Control group \\
\hline \multicolumn{3}{|l|}{ Dependent variables } \\
\hline Somatization & Negative $=I$; positive $=2$ & No \\
\hline Obsessive-compulsive symptoms & Negative $=1$; positive $=2$ & No \\
\hline Job satisfaction & Unsatisfactory $=\mathrm{l}$; satisfactory $=2$ & No \\
\hline \multicolumn{3}{|l|}{ Independent variables } \\
\hline Gender & Male $=1 ;$ female $=2$ & Male \\
\hline Marital status & Married =1; others $=2$ & Married \\
\hline Age & $\leq 30=00 ; 31-45=\mid 0 ; 46-60=01$ & $\leq 30$ \\
\hline Educational level & $<$ Bachelor's degree $=\mathrm{I} ; \geq$ Bachelor's degree $=2$ & $<$ Bachelor's degree \\
\hline Employment length & $\leq 3$ years $=00 ; 4-10$ years $=10 ; \geq 11$ years $=01$ & $\leq 3$ years \\
\hline
\end{tabular}

Abbreviation: PMW, prison medical worker.

Table 3 Logistic regression analysis of influence factors associated with respondents' somatization

\begin{tabular}{|c|c|c|c|c|}
\hline \multirow[t]{2}{*}{ Demographics } & \multirow{2}{*}{$\begin{array}{l}\text { Negative } \\
\mathrm{n}=255 \text { (77.27\%) } \\
\end{array}$} & \multirow{2}{*}{$\begin{array}{l}\text { Positive } \\
n=75(22.73 \%)\end{array}$} & \multirow[t]{2}{*}{ COR $(95 \% \mathrm{Cl})$} & \multirow[t]{2}{*}{ AOR (95\% Cl) } \\
\hline & & & & \\
\hline \multicolumn{5}{|l|}{ Gender } \\
\hline Male & II 14 (74.5I) & 39 (25.49) & - & - \\
\hline Female & $14 \mid(79.66)$ & $36(20.34)$ & $0.75(0.45-1.25)$ & $0.96(0.49-1.88)$ \\
\hline \multicolumn{5}{|l|}{ Marital status } \\
\hline Married & I 79 (77.49) & $52(22.5 I)$ & - & - \\
\hline Others & $76(76.77)$ & $23(23.23)$ & $1.04(0.60-1.82)$ & $1.32(0.48-3.62)$ \\
\hline \multicolumn{5}{|l|}{ Age } \\
\hline$\leq 30$ & 118 (83.69) & $23(16.31)$ & - & - \\
\hline $31-45$ & $121(77.56)$ & $35(22.44)$ & $\mathrm{I} .48(0.83-2.66)$ & I.8I (2.77-2।.97)* \\
\hline $46-60$ & $16(48.48)$ & $17(51.52)$ & $5.45(2.4 \mid-12.33)^{*}$ & $30.44(7.08-130.92)^{*}$ \\
\hline \multicolumn{5}{|l|}{ Education level } \\
\hline$<$ Bachelor's degree & $36(52.17)$ & $33(47.83)$ & - & - \\
\hline$\geq$ Bachelor's degree & $219(83.91)$ & $42(16.09)$ & $0.21(0.12-0.37)^{*}$ & $0.23(0.11-0.48)^{*}$ \\
\hline \multicolumn{5}{|l|}{ Employment length } \\
\hline$\leq 3$ years & $44(73.33)$ & $16(26.67)$ & - & - \\
\hline 4-10 yeas & 101 (76.52) & 31 (23.48) & $0.84(0.42-1.70)$ & $0.54(0.22-1.33)$ \\
\hline$\geq I I$ years & 110 (79.7I) & $28(20.29)$ & $0.70(0.35-1.42)$ & $0.14(0.04-0.44)^{* *}$ \\
\hline
\end{tabular}

Notes: *p-value $<0.001$, **p-value $<0.01$

Abbreviations: AOR, adjusted odds ratio; COR, crude odds ratio.

as independent variables. The variables' assignments are summarized in Table 2.

Table 3 lists some risk factors potentially associated with respondents' somatization. Our univariate analysis showed that the top 2 factors affecting the respondents' somatization were PMWs' age (age 46 60, COR $=5.45,95 \% \mathrm{CI}$ : 2.41-12.33) and educational level (COR $=0.21,95 \% \mathrm{CI}$ : $0.12-0.37)$. In addition, multivariate logistic regression analysis revealed that positive results of PMWs' somatization were mainly detected in the age groups of $31-45$ years (AOR $=1.81,95 \%$ CI: $2.77-21.97)$ and $46-60$ years $(\mathrm{AOR}=30.44$, 95\% CI: 7.08-130.92). PMWs with higher educational level had lower positive detection rate of somatization (AOR $=0.23,95 \%$ CI: $0.11-0.48)$. Moreover, PMWs with 11 years or longer employment history had a lower positive detection rate of somatization $(\mathrm{AOR}=0.14,95 \% \mathrm{CI}$ : $0.04-0.44)$.

\section{Factors associated with PMWs' obsessive-compulsive symptoms}

Table 4 summarizes the main factors associated with the detection of the PMWs' obsessive-compulsive symptoms. Univariate logistic regression showed that PMWs' marital status, age, education level, and length of employment all had an impact on the detection results. The multivariable logistic regression demonstrated that the following: 1) compared with the married PMWs, other PMWs (including those who were spinsters, divorced, widowed, or single) had higher risk of developing the obsessive-compulsive symptoms $(\mathrm{AOR}=1.65$, 
Table 4 Logistic regression analysis of possible factors associated with PMWs' obsessive-compulsive symptoms

\begin{tabular}{|c|c|c|c|c|}
\hline \multirow[t]{2}{*}{ Demographics } & \multirow{2}{*}{$\begin{array}{l}\text { Negative } \\
\mathrm{n}=174(52.73 \%)\end{array}$} & \multirow{2}{*}{$\begin{array}{l}\text { Positive } \\
n=156(47.27 \%)\end{array}$} & \multirow[t]{2}{*}{ COR (95\%Cl) } & \multirow[t]{2}{*}{ AOR $(95 \% \mathrm{Cl})$} \\
\hline & & & & \\
\hline \multicolumn{5}{|l|}{ Gender } \\
\hline Male & $87(56.86)$ & $66(43.14)$ & - & - \\
\hline Female & $87(49.15)$ & $90(50.85)$ & $1.36(0.88-2.1 \mathrm{I})$ & $1.38(0.82-2.33)$ \\
\hline \multicolumn{5}{|l|}{ Marital status } \\
\hline Married & |3| (56.7I) & $100(43.29)$ & - & - \\
\hline Others & $43(43.43)$ & $56(56.57)$ & $1.71(1.06-2.74)^{*}$ & $1.65(1.32-3.32)^{*}$ \\
\hline \multicolumn{5}{|l|}{ Age } \\
\hline$\leq 30$ & $66(46.8 I)$ & $75(53.19)$ & - & - \\
\hline $31-45$ & $92(58.97)$ & $64(41.03)$ & $0.6 \mathrm{I}(0.39-0.97)^{*}$ & $1.71(0.85-3.44)$ \\
\hline $46-60$ & $16(48.48)$ & $17(5 \mid .52)$ & $0.94(0.44-2.00)$ & $2.33(0.72-7.49)$ \\
\hline \multicolumn{5}{|l|}{ Education level } \\
\hline$<$ Bachelor's degree & $17(24.64)$ & $52(75.36)$ & - & - \\
\hline$\geq$ Bachelor's degree & $157(60.15)$ & $104(39.85)$ & $0.22(0.12-0.40)^{* *}$ & $0.25(0.13-0.51)^{* *}$ \\
\hline \multicolumn{5}{|l|}{ Employment length } \\
\hline$\leq 3$ years & $18(30.00)$ & $42(70.00)$ & - & - \\
\hline $4-10$ yeas & $66(50.00)$ & $66(50.00)$ & $0.43(0.22-0.82)^{* * *}$ & $0.47(0.23-0.97)^{*}$ \\
\hline$\geq I I$ years & $90(65.22)$ & $48(34.78)$ & $0.23(0.12-0.44)^{* *}$ & $0.15(0.06-0.39)^{* *}$ \\
\hline
\end{tabular}

Notes: $* p$-value $<0.05, * *$-value $<0.00 \mathrm{I}$, $* * *$-value $<0.01$.

Abbreviations: AOR, adjusted odds ratio; COR, crude odds ratio; PMW, prison medical worker.

Table 5 Logistic regression analysis of possible factors associated with PMWs' job satisfaction

\begin{tabular}{|c|c|c|c|c|}
\hline \multirow[t]{2}{*}{ Demographics } & \multirow{2}{*}{$\frac{\text { Unsatisfactory }}{n=165(50.00 \%)}$} & \multirow{2}{*}{$\frac{\text { Satisfactory }}{n=165(50.00 \%)}$} & \multirow[t]{2}{*}{ COR $(95 \% \mathrm{Cl})$} & \multirow[t]{2}{*}{ AOR (95\% Cl) } \\
\hline & & & & \\
\hline \multicolumn{5}{|l|}{ Gender } \\
\hline Male & $17(11.11)$ & 136 (88.89) & - & - \\
\hline Female & I 48 (83.62) & $29(16.38)$ & $0.02(0.0 \mathrm{I}-0.05)^{*}$ & $0.01(0.004-0.03)^{*}$ \\
\hline \multicolumn{5}{|l|}{ Marital status } \\
\hline Married & $83(35.93)$ & I 48 (64.07) & - & - \\
\hline Single & $82(82.83)$ & $17(17.17)$ & $0.12(0.07-0.21)^{*}$ & $0.61(0.19-2.01)$ \\
\hline \multicolumn{5}{|l|}{ Age } \\
\hline$\leq 30$ & $106(75.18)$ & $35(24.82)$ & - & - \\
\hline $1-45$ & $54(34.62)$ & $102(65.38)$ & $5.72(3.45-9.48)^{*}$ & $2.75(1.96-7.88)^{* *}$ \\
\hline $46-60$ & $5(15.15)$ & $28(84.85)$ & $16.96(6.08-47.29)^{*}$ & $5.60(0.65-48.37)$ \\
\hline \multicolumn{5}{|l|}{ Education level } \\
\hline$<$ Bachelor's degree & $44(63.77)$ & $25(36.23)$ & - & - \\
\hline$\geq$ Bachelor's degree & $|2|(46.36)$ & 140 (53.64) & $2.04(1.18-3.52)^{* *}$ & $1.72(0.45-6.65)$ \\
\hline \multicolumn{5}{|l|}{ Employment length } \\
\hline$\leq 3$ years & 55 (91.67) & $5(8.33)$ & - & - \\
\hline 4-10 yeas & $63(47.73)$ & $69(52.27)$ & $12.05(4.54-32.01)^{*}$ & $6.03(1.43-25.38)^{* * * *}$ \\
\hline$\geq$ II years & $47(34.06)$ & 91 (65.94) & $21.30(7.99-56.80)^{*}$ & $19.95(3.36-118.36)^{*}$ \\
\hline
\end{tabular}

Notes: ${ }^{*}$-value $<0.001$, ${ }^{* *} p$-value $<0.05$, ${ }^{* * *}$-value $<0.01$.

Abbreviations: AOR, adjusted odds ratio; $\mathrm{COR}$, crude odds ratio; PMW, prison medical worker.

Table 6 Correlations between somatization, obsessive-compulsive symptoms, and job satisfaction among the PMWs

\begin{tabular}{llll}
\hline Variables & Somatization & Obsessive-compulsive symptoms & Job satisfaction \\
\hline Somatization & $\mathrm{I}$ & - & - \\
Obsessive-compulsive symptoms & $0.77^{*}$ & $\mathrm{I}$ & - \\
Job satisfaction & $-0.29^{*}$ & $-0.79^{*}$ & $\mathrm{I}$ \\
\hline
\end{tabular}

Notes: *Correlation is significant at the 0.01 level (2-tailed).

Abbreviation: PMW, prison medical worker. 
95\% CI: 1.32-3.32); 2) PMWs with higher educational level had lower positive detection rate of obsessive-compulsive symptoms $(\mathrm{AOR}=0.25,95 \% \mathrm{CI}$ : 0.13-0.51). 3) PMWs with service history of 4-10 years or longer may present slighter obsessive-compulsive symptoms (4-10 years, AOR $=0.47,95 \%$ CI: $0.23-0.97 ; \geq 11$ years, $\mathrm{AOR}=0.15,95 \% \mathrm{CI}$ : 0.06-0.39).

\section{Factors associated with PMWs' job satisfaction}

According to the 7-point Likert scale, score of between 1 and 3 points was considered to be unsatisfactory, and a score between 4 and 7 points was considered to be satisfactory. Table 5 lists the CORs obtained from univariate logistic regression analyses and AORs from multivariable logistic regression model with the $95 \%$ CIs. Univariate analysis showed that PMWs' gender, marital status, age, education level, and length of employment had an effect on the detection results. However, marital status and education level did not appear to be a significant factor in the multivariable analysis. We found the following: 1) female PMWs' job satisfactory rate was lower than the males $(\mathrm{AOR}=0.01$, 95\% CI: $0.004-0.03)$; 2) the age group 31-45 had higher job satisfactory rate than those aged $\leq 30$ (AOR $=2.75,95 \%$ CI: 1.96-7.88); 3) PMWs with service history of 4-10 years or longer had the higher job satisfactory rate (4-10 years, $\mathrm{AOR}=6.03,95 \% \mathrm{CI}: 1.43-25.38 ; \geq 11$ years, $\mathrm{AOR}=19.95$, 95\% CI: 3.36-118.36).

\section{Correlations between somatization, obsessive-compulsive symptoms, and job satisfaction among the PMWs}

The Spearman's rank correlation was used to evaluate the possible association between somatization, obsessive-compulsive symptoms, and job satisfaction among the PMWs. Our analyses showed that there was a strong positive correlation between somatization and obsessive-compulsive symptoms, low negative correlation between somatization and job satisfaction, and strong negative correlation between job satisfaction and obsessive-compulsive symptoms among the PMWs. The Spearman's rank correlation coefficients were $0.77,-0.29$, and -0.79 , respectively (Table 6).

\section{Discussion}

Mental health is a major public health and social problem that affects economic and social development. ${ }^{17}$ Mental health is an indispensable part of health that has an effect on people's daily life, behaviors, emotional well-being, and even physical health. It is estimated that about $14 \%$ of the global burden of disease is attributed to mental health disorders. ${ }^{18}$ The World Health Organization launched the “2013-2020 Comprehensive Mental Health Action Plan" to emphasize the importance of mental health. ${ }^{19}$ As the world's most populated country, the mental health problems in China have attracted much attention. ${ }^{20}$ The data provided by the National Health and Family Planning Commission of the People's Republic of China show that mental disorders rank first among the total burden of disease in China, and the prevalence of mental disorders in China is still rising rapidly, especially somatization, obsessive-compulsive disorder, and depression. ${ }^{21}$ Furthermore, there is a higher prevalence risk for these diseases among some special occupational groups, like the military men, policemen, and the PMWs.

Hence, we particularly evaluated the current status of PMWs' somatization, obsessive-compulsive symptoms, and their job satisfaction by this cross-sectional survey study in Jiangxi province of China along with assessing the possible influencing factors. This study is a starting point to draw the public's attention to PMWs, including their physical fitness, mental health, and working conditions. Findings from this study will also provide baseline information useful to the local, regional, and even national governments of other nations in their attempt to manage PMWs' concerns and problems more scientifically and effectively in future. The basic information of the participants in the present study was consistent with the actual situation of PMWs in Jiangxi province, which shows that the sample of this study is well represented.

However, as the first study addressing PMWs' mental health in China, there are several limitations in this study. First, some information like the PMWs' income, working condition factors, related general demographic information of the prisoners etc were not assessed. Furthermore, some existing studies have shown that health-related quality of life and support from the social network and community may lead to a series of psychological problems such as somatization, obsessive-compulsive symptoms, despondence, anxiety, etc. ${ }^{24-26}$ However, these contents were not investigated in this study. Hence, further research is recommended to conduct more in-depth explorations on these aspects with a more scientific, rational, and rigorous design, like cohort studies or case-control studies with use of the Social Support Rating Scale or other survey tools to properly address these conundrums. Lastly, there are few studies that have investigated the various psychological problems faced by PMWs and the symptoms of psychopathology in China. Hence, future 
studies are essential in order to confirm these findings from the present paper.

In the present study, we reported that the positive detection rates of PMWs' somatization and obsessive-compulsive disorder were $22.73 \%$ and $47.27 \%$, respectively (Tables 3 and 4), indicating the PMWs are facing higher risk and suffering serious psychological problems with psychopathology symptoms. Those with lower educational level, the elderly, and new employees are particularly vulnerable to somatization and obsessive-compulsive symptoms. Our findings are consistent with previous studies showing that the elderly may have more psychological problems. ${ }^{8,22}$ This may be due to the weakened body function and decreased physical health condition associated with aging. Compared to the better-educated PMWs, those with lower educational level may lack the means and ability to acquire the relevant knowledge to better manage and improve their own emotions. It is interesting to note that senior employees with longer service history in prisons have lower risk of suffering somatization symptoms and obsessive-compulsive disorders. In addition, marital status is a protective factor that reduces the risk of having obsessive-compulsive symptoms in PMWs.

One of the major findings from this study is that half of the PMWs were not satisfied with their current job, particularly the female workers and young workers with a short service history. A follow on interview was conducted with several PMWs from the Provincial Prison Central Hospital of Jiangxi which revealed the following possible reasons: 1) female PMWs have less promotion opportunities than the male PMWs, 2) females have lower income than their male colleagues with the same workloads on average, 3 ) relatively isolated working environments and hazardous working conditions, 4) generally, women in China are still expected to spend more time at home taking care of the families. On the other hand, most young staff were just starting their new job, and their current job might quite different from, or even completely contrary to, their expectations. Thus, the gap between their ideal work and their actual job has emerged to be a negative impact. Another interesting finding associated with young PMWs during the interview is that some young staff even started to worry about finding a spouse if they do not change their PMW job.

In accordance with previous studies, the present paper showed that association between PMWs' somatization and obsessive-compulsive symptoms is strongly positively correlated. ${ }^{23}$ Our finding supports that PMWs' job satisfaction and somatization symptoms have negative interactions with each other, and the same was observed between somatization symptoms and obsessive-compulsive disorders. These results suggest that humanistic care and social support are needed for this special occupational group. Moreover, the relevant government departments, especially the public security and judicial administration and police departments, need to provide more financial support and meet their spiritual needs. The prisons and its affiliated hospitals or health centers should organize multiple social activities and communicate about the mental health and its education. All these corresponding measures may improve the PMWs' job satisfaction, and thus their mental health state.

Given the high-risk factors leading to poor mental health conditions of PMWs, the job satisfaction is negatively correlated with mental health. Hence, targeted measures should be implemented to improve PMWs' job satisfaction in order to reduce their mental health risks. The somatization, obsessive-compulsive symptoms, and job satisfaction of PMWs showed variation between different populations, which may suggest the different policies or approaches to working with these populations. Some specific approaches include the following: 1) regularly assess the mental health status of PMWs and encourage their family members and friends to provide emotional and psychological support in time, 2) intensify the psychological counseling measures and improve their mental health in all aspects, especially for those with lower educational level, the elderly, and new employees, 3) highlight the induction and orientation programs for female and young PMWs with a short service time, and 4) ensure that new employees receive relative counseling and job training. In addition, follow-up studies will be necessary to look for more practical ways to improve PMWs' mental health status and enhance job satisfaction.

\section{Conclusion}

This study has clearly shown that the PMWs have the higher risk and more serious somatization and obsessive-compulsive symptoms, especially those with lower educational level, the elderly, and new employees. Marital status is a protective factor that reduces the risk of having obsessive-compulsive symptoms in PMWs. In addition, half of the PMWs were not satisfied with their current job, particularly the female workers and young staff with a short history of service. PMWs' somatization and obsessive-compulsive symptoms are strongly positively correlated with each other. PMWs' job satisfaction is negatively correlated with having somatization symptoms and obsessive-compulsive disorders. The findings 
from this study indicated that the improvement of job satisfaction is important and necessary in order to reduce the somatization symptoms and obsessive-compulsive disorders among PMWs.

This study is designed to be the first step in developing a model of the social dilemma of PMWs' mental health and job satisfaction in China. This study will become a starting point to draw the public's attention to PMWs, including their physical fitness, mental health, and working conditions. Findings from this study will also provide the baseline information useful to the local, regional, and even national governments of other nations in their attempt to manage PMWs' concerns and problems more scientifically and effectively in the future.

\section{Acknowledgments}

This study was supported by an internal grant from Wuhan University. We thank Dr Xuan Luo, Director of the Provincial Prison Central Hospital of Jiangxi, for her assistance with data collection. We also gratefully acknowledge the assistance and cooperation from the related authorities and the research participants (especially the Provincial Prison Central Hospital of Jiangxi and Nanchang University) who contributed their time and effort for this study.

\section{Author contributions}

Xiaojun Liu and Zongfu Mao designed this study; Xiaojun Liu collected data and conducted the data analysis; Xiaojun Liu, Baojing Li, and Dongdong Jiang drafted the paper; Yuanan Lu, Zongfu Mao, and Xiaojun Liu revised the manuscript. All authors contributed toward data analysis, drafting and critically revising the paper and agree to be accountable for all aspects of the work.

\section{Disclosure}

The authors report no conflicts of interest in this work.

\section{References}

1. Liu L, Cohen S, Schulz MS, Waldinger RJ. Sources of somatization: exploring the roles of insecurity in relationships and styles of anger experience and expression. Soc Sci Med. 2011;73(9):1436-1443.

2. Besteher B, Gaser C, Langbein K, Dietzek M, Sauer H, Nenadi I. Effects of subclinical depression, anxiety and somatization on brain structure in healthy subjects. J Affect Disord. 2017;215:111-117.

3. Sun J, Li Z, Buys N, Storch EA. Correlates of comorbid depression, anxiety and helplessness with obsessive-compulsive disorder in Chinese adolescents. J Affect Disord. 2015;174:31-37.

4. Albert U, Baffa A, Maina G. Family accommodation in adult obsessivecompulsive disorder: clinical perspectives. Psychol Res Behav Manag. 2017;10:293-304.
5. Auerbach RP, Alonso J, Axinn WG, et al. Mental disorders among college students in the World Health Organization World Mental Health Surveys-corrigendum. Psychol Med. 2016;46(14):2955-2970.

6. Pachucki MC, Ozer EJ, Barrat A, Cattuto C. Mental health and social networks in early adolescence: a dynamic study of objectively-measured social interaction behaviors. Soc Sci Med. 2015;125(12):40-50.

7. Mckibben JB, Fullerton CS, Herberman Mash HB, et al. Suicidal behaviors and the use of mental health services among active duty Army soldiers. Psychiatr Serv. 2014;65(3):374-380.

8. Wang S, Ungvari GS, Forester BP, et al. Gender differences in general mental health, smoking, drinking and chronic diseases in older adults in Jilin province, China. Psychiatry Res. 2017;251:58-62.

9. Scott KM, Lim C, Al-Hamzawi A, et al. Association of mental disorders with subsequent chronic physical conditions: world mental health surveys from 17 countries. JAMA Psychiat. 2016;73(2):150-158.

10. Hui CO, Ibrahim N, Wahab S. Psychological distress, perceived stigma, and coping among caregivers of patients with schizophrenia. Psychol Res Behav Manag. 2016;9:211-218.

11. Wang ZY. [Symptom checklist (SCL-90)]. Shanghai Psychiatry. 1984;2:805-808. Chinese.

12. Jin H, Wu WY, Zhang MY. [Study on SCL-90 assessment of normal Chinese in China]. Chin J Nerv Ment Dis. 1986;(5):260-263. Chinese.

13. Tang QP, Cheng ZH, Yuan AH. The use and reanalysis of SCL-90 in China. Chin J Clin Psychol. 1999;1:16-20.

14. Zhang J, Zhang X. Chinese college students' SCL-90 scores and their relations to the college performance. Asian J Psychiatr. 2013;6(2):134-140.

15. Chen F, Wang L, Heeramun-Aubeeluck A, et al. Identification and characterization of college students with attenuated psychosis syndrome in China. Psychiatry Res. 2014;216(3):346-350.

16. Tan H, Lan XM, Yu NL, Yang XC. Reliability and validity assessment of the revised Symptom Checklist 90 for alopecia areata patients in China. J Dermatol. 2015;42(10):975-980.

17. Elmore D. Essential role of public health policies in addressing mental health and trauma. Am J Public Health. 2015;104(2):60-67.

18. Howard LM, Piot P, Stein A. No health without perinatal mental health. Lancet. 2014;384(9956):1723-1724.

19. Saxena S, Funk M, Chisholm D. World Health Assembly adopts Comprehensive Mental Health Action Plan 2013-2020. Lancet. 2013;381(9882):1970.

20. Li K, Sun X, Zhang Y, Kolstad A. Mental health care in China: review on the delivery and policy issues in 1949-2009 and the outlook for, the next decade. Acta Neuropsychiatr. 2014;26(3):134-145.

21. NHFPCC. Interpretation of the Policy Guidelines on Strengthening Guidance on Mental Health Services. People's Republic of China: National Health and Family Planning Commission of People's Republic of China. 2017. Available from: http://www.nhfpc.gov.cn/zwgk/jdjd/20 1701/10ea6b89740344199bfb24e891 ca5564.shtml. Accessed February 25,2018 .

22. Dong X, Simon M. Prevalence of elder self-neglect in a Chicago Chinese population: the role of cognitive physical and mental health. Geriatr Gerontol Int. 2015;16(9):1051-1062.

23. Sereda Y, Dembitskyi S. Validity assessment of the symptom checklist SCL-90-R and shortened versions for the general population in Ukraine. BMC Psychiatry. 2016;16(1):300.

24. Cao X, Chen L, Tian L, et al. Psychological distress and health-related quality of life in relocated and nonrelocated older survivors after the 2008 Sichuan earthquake. Asian Nurs Res. 2015;9(4):271-277.

25. Yoo ES, Kim BS, Kim DY, Oh SJ, Kim JC. The impact of overactive bladder on health-related quality of life, sexual life and psychological health in Korea. Int Neurourol J. 2011;15(3):143-151.

26. Yohannes AM, Doherty P, Bundy C, Yalfani A. The long-term benefits of cardiac rehabilitation on depression, anxiety, physical activity and quality of life. J Clin Nurs. 2010;19(19-20):2806-2813. 
Psychology Research and Behavior Management is an international, peerreviewed, open access journal focusing on the science of psychology and its application in behavior management to develop improved outcomes in the clinical, educational, sports and business arenas. Specific topics covered in the journal include: Neuroscience, memory and decision making; Behavior modification and management; Clinical applications; Business and sports performance management; Social and developmental studies; Animal studies. The manuscript management system is completely online and includes a very quick and fair peer-review system, which is all easy to use. Visit http://www. dovepress.com/testimonials.php to read real quotes from published authors.

Submit your manuscript here: https://www.dovepress.com/psychology-research-and-behavior-management-journal 